\title{
L/S Ratio and Cortisol in Amniotic Fluid According to Gestational Age
}

\author{
RAÚL BUSTOS AND GUSTAVO GIUSSI ${ }^{(20)}$ \\ Latin American Center of Perinatology and Human Development, Pan American Health Organization, World Health \\ Organization, Montevideo, Uruguay
}

\begin{abstract}
Summary
It is well known that corticoids act to induce fetal lung maturation when administered to the fetus or mother. However, their physiologic role has been recently questioned with regard to stimulation of surfactant production.

We investigated the process of fetal lung maturation to determine whether or not it is associated with changes in amniotic fluid cortisol.

Sixty-two amniotic fluid samples from 53 patients were obtained by transabdominal amniocentesis strictly due to maternal and/or fetal clinical indication, according to the course of pregnancy and the maternal and/or fetal status.

The $L / S$ ratio was measured on thin-layer plates by reflectance densitometry and calculated as previously described by Gluck $\boldsymbol{e t}$ al.

Cortisol levels in amniotic fluid were measured by radioimmunoassay using commercial reagent kits (Gamma coat $\mathrm{I}^{125}$ cortisol; Clinical Assays, Inc.).

The level of amniotic fluid cortisol increased with gestational age from wk 30 to 41; a sharp increment was observed at 39 to 41 wk.

No significant differences were found when the mean values of cortisol were compared at wk 30 to 32,33 to 35 , and 36 to 38 . When the fourth group was included ( 39 to $41 \mathrm{wk}$ ), a statistically significant difference was found $(F=4.63 ; P<0.01)$.

There was a progressive increase in $L / S$ ratio during gestation as has already been described, plus a value greater than 2 was found during the 33 to 35 wk period. The statistical analysis performed on $\mathrm{L} / \mathrm{S}$ ratios at weekly intervals 30 to 32,33 to 35 , and 36 to 38 showed a significant difference in the mean values in the groups studied $(F=6.84 ; P<0.005)$.

Therefore, the increment of $L / S$ ratio over 2 was already observed during the 33 to 35 wk period of gestation, whereas the mean cortisol amniotic fluid values remained unchanged between the 30th and the 38th wk. The cortisol peak was observed only during the 39 to 41 wk period.
\end{abstract}

\section{Speculation}

It has been demonstrated that glucocorticoids have an important role in accelerating the process of the development of fetal lung maturation. The physiologic fetal lung surfactant production does not necessarily depend on the increase of fetal cortisol levels. It is speculated that cortisol has a permissive role which allows the action of other hormones.

It has been suggested, through clinical observations (10) and experimental studies (12-17) that glucocorticoids have an important role in the normal process of biochemical development of the fetal lung.

A rise in the amniotic fluid cortisol level with increasing gestational age has been shown $(4,5,15)$. It is also well known that the lecithin/sphingomyelin (L/S) ratio in amniotic fluid increases with gestational age and that its determination is one of the best tests for evaluating fetal lung maturation (7).

It has been shown that the increased $\mathrm{L} / \mathrm{S}$ ratio that occurs with increased gestational age is accompanied by greater cortisol values in amniotic fluid (4).

Furthermore, maternal administration of glucocorticoids produces an increase in the $\mathrm{L} / \mathrm{S}$ ratio in amniotic fluid, as well as a reduction in the incidence of respiratory distress syndrome (RDS) in the preterm newborn (1).

Although it is well known that corticoids act to induce fetal lung maturation when given to the fetus or mother, their physiologic role has recently been questioned with regard to stimulation of surfactant production. Animal experiments have shown that the increase in surfactant production is not preceded by an increase in cortisol levels, even though there is an increment of other hormones (11).

Therefore, we investigated the process of fetal lung maturation to determine whether or not it is associated with changes in amniotic fluid cortisol.

\section{MATERIALS AND METHODS}

Sixty-two amniotic fluid samples from 53 patients were obtained by transabdominal amniocentesis strictly due to maternal and/or fetal clinical indication, according to the course of pregnancy and the maternal and/or fetal status.

All patients had complicated pregnancies due mainly to diabetes and to Rh-negative sensitization (Table 1).

Samples taken from patients with polyhydramnios and contaminated by meconium or blood were excluded from our study.

Amniotic fluid samples were $10 \mathrm{ml}$ or more. Phospholipids and cortisol were measured after centrifugation at $3500 \mathrm{rpm}$ for 10 $\min$.

Extraction of phospholipids from amniotic fluid supernatant was performed using the procedure described by Gluck et al. (6).

After extraction, acetone precipitation was done, and both fractions (acetone-precipitated and acetone-soluble) were plated and run on heated, activated thin layers of silica gel $\mathrm{H}$ containing $5 \%$ ammonium sulfate.

The acetone-precipitated fraction was developed on one-dimensional thin-layer chromatography using chloroform-methanolacetic acid- $\mathrm{H}_{2} \mathrm{O}(390-150-48-24 \mathrm{v} / \mathrm{v})$.

After development of the chromatograms the plates were charred at $280^{\circ} \mathrm{C}$ for $10 \mathrm{~min}$ to visualize the compounds. The $\mathrm{L} /$ $S$ ratio was measured on the thin-layer plates by reflectance densitometry and calculated as previously described by Gluck $e t$ al. (7).

Cortisol levels in amniotic fluid were measured by radioimmunoassay (4) using commercial reagents kits (Gamma coat $\mathrm{I}^{125}$ cortisol; Clinical Assays, Inc.).

\section{RESULTS}

The relationship among amniotic fluid cortisol levels, $\mathrm{L} / \mathrm{S}$ ratio, and gestational age is shown in Figure 1. 
The level of amniotic fluid cortisol increased with gestational age from wk 30 to 41 ; a sharp increment is observed at 39 to 41 wk.

Samples were divided into four groups according to gestational age for statistical purposes. Mean values, standard deviations, and standard errors were calculated for each group.

No significant differences were found when the mean values of cortisol were compared at wk 30 to 32,33 to 35 , and 36 to 38 (Fig. 2). When the fourth group was included ( 39 to $41 \mathrm{wk}$ ), a statistically significant difference was found ( $F=4.63 ; P<0.01$ ) (Fig. 1).

A similar tendency was observed when the $\mathrm{L} / \mathrm{S}$ ratio was analyzed in relation to gestational age (Fig. 1).

There was a progressive increase during gestation as has already been described. The L/S ratio was already found to be greater than 2 during the 33 to $35 \mathrm{wk}$ period. A statistical analysis of the $\mathrm{L} / \mathrm{S}$ ratio at weekly intervals 30 to 32,33 to 35 , and 36 to 38 showed a significant difference in the mean values in the groups studied. $(F=6.84 ; P<0.005)$ (Fig. 3).

Therefore, a $\mathrm{L} / \mathrm{S}$ ratio greater than 2 had already been observed during the 33 to $35 \mathrm{wk}$ period of gestation, whereas the mean

Table 1. Distribution of associated pathologies

\begin{tabular}{lr} 
Chronic hypertension & 7 \\
Diabetes B and C & 6 \\
Diabetes D, F, R & 6 \\
Rh sensitization & 10 \\
Rh sensitization + hypertension & 1 \\
Rh sensitization + diabetes & 2 \\
Other pathologies & 21 \\
Total & 53 \\
\hline
\end{tabular}

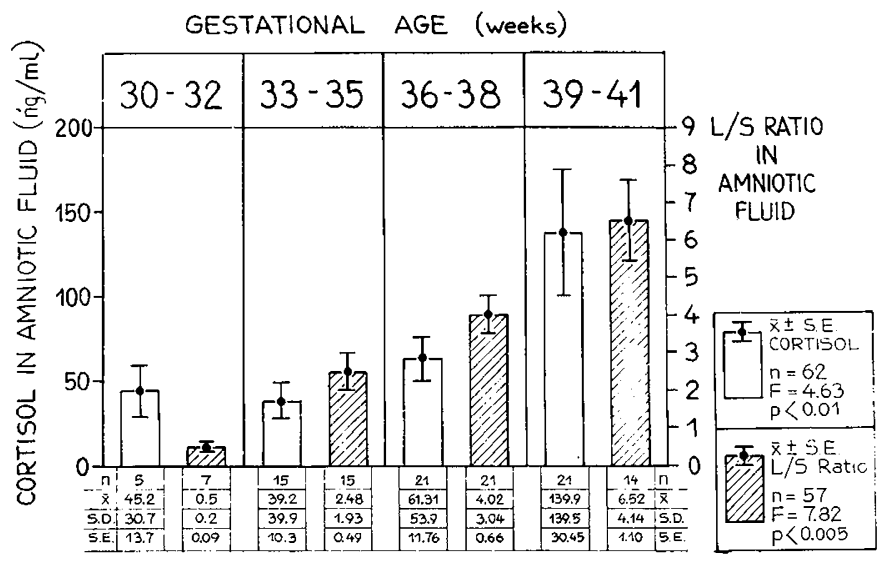

Fig. 1. The level of amniotic fluid $\mathrm{L} / \mathrm{S}$ ratio increases along gestation. The mean value of amniotic fluid cortisol remains unchanged until the 36 to $38 \mathrm{wk}$ period, showing a sharp increment at the end of pregnancy.

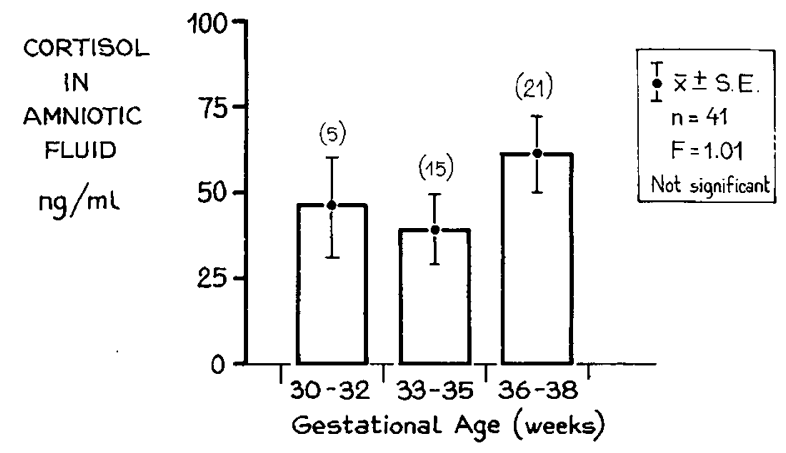

Fig. 2. No significant differences were observed in the mean values of cortisol between the different periods compared.

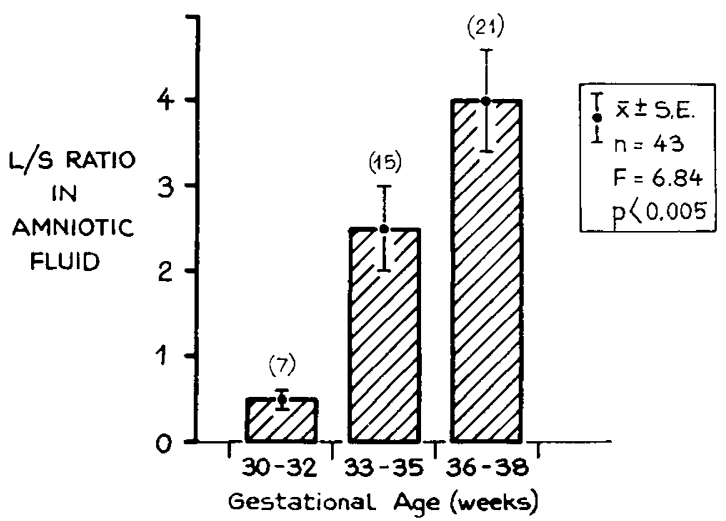

Fig. 3. The statistical analysis showed a significant difference between $\mathrm{L} / \mathrm{S}$ ratio mean values of the studied groups.

cortisol amniotic fluid values remained unchanged between wk 30 and 38 . The cortisol peak was observed only during the 39 to 41 wk period.

\section{DISCUSSION}

Liggins (9) proposed that glucocorticoids have an important role in the maturation of the sheep fetal lung.

Corticosteroids have been used in human patients, in cases of threatened premature labor, to hasten the maturating process of the lung of the fetus (10).

Cortisol levels in umbilical cord blood of newborns in whom RDS subsequently developed were found lower than that in newborns of comparable gestational age without the syndrome (14).

It has been reported that the activity of cholinephosphotransferase in the fetal lung increased during normal gestation in the rat (2) and mouse (16). In the fetal rabbit, this activity was stimulated by the administration of glucocorticosteroids (3), although this has not been observed by other authors $(18,19)$.

However, there is no direct evidence that fetal cortisol is the primary stimulus of augmented surfactant synthesis in the human fetus. Indeed, no relation was found between the level of cord plasma cortisol and the development of RDS (8).

The results of Mescher et al. (11) showed that the rise in fetal plasma cortisol production during gestation occurs after the rise in surfactant in tracheal effluent in fetal sheep.

It has been reported that a sharp increase in total amniotic fluid cortisol occurs after the 34 th wk of gestation (4). However, our results show that this rise occurs at wk 38 after an increase in the $\mathrm{L} / \mathrm{S}$ ratio has been produced.

The difference between the results of Fencl and Tulchinsky (4) and ours could possibly be explained by the wide interval of gestational age used by these authors ( 20 to 34 and 35 to $40 \mathrm{wk}$ ), as compared with the short period used in our study (2-wk intervals).

The increase in umbilical artery blood cortisol level around the 36 th wk of gestation reported by Murphy (13) may be interpreted as preceding the rise in amniotic fluid cortisol.

Because there are conflicting reports about the effects of corticosteroids on the process of fetal lung maturation, their role has not yet been clearly established. Cortisol may have a permissive role in fetal lung maturation which allows the action of other hormones.

The results of our present study lead us to conclude that the elevation of $\mathrm{L} / \mathrm{S}$ ratio observed between the 30 th and 38 th wk of gestation was not accompanied by a previous or simultaneous increase in amniotic fluid cortisol level.

These results support findings made in animal experiments (11) and suggest that fetal lung surfactant production does not necessarily depend on the increase of fetal cortisol levels. 


\section{REFERENCES AND NOTES}

1. Caspi, E., Schreyer, P., Weinbraub, Z., Bukovsky, I., and Tamir, I.: Changes in amniotic fluid lecithin/sphingomyelin ratio following maternal dexamethasone administration. Am. J. Obstet. Gynecol., 122: 327 (1975).

2. Farrell. P. M., Lundgren. D. W., and Adams, A. J.: Choline kinase and choline phosphotransferase in developing fetal rat lung. Biochem. Biophys. Res. Commun., 57: 696 (1974)

3. Farrell, P. M., and Zachman, R. D. Induction of choline phosphotransferase and lecithin synthesis in fetal lung by corticosteroids. Science (Wash. D. C.), 179: 297 (1973).

4. Fencl, M., De M., and Tulchinsky, D.: Total cortisol in amniotic fluid and fetal lung maturation. N. Engl. J. Med., 292: 133 (1975).

5. Gewolb, I. H., Hobbins, J. C., and Tan, S. Y.: Amniotic fluid cortisol as an index of fetal lung maturity. Obstet. Gynecol., 49: 462 (1977).

6. Gluck, L., Kulovich, M. V., and Borer, R. C.: Estimates of fetal lung maturity. Clin. Perinatol., $1: 125$ (1974).

7. Gluck, L., Kulovich, M. V., Borer, R. C., Jr., and Keidel, W. N.: The interpretation and significance of the lecithin sphingomyelin ratio in amniotic fluid. Am. J. Obstet. Gynecol., 120: 142 (1974).

8. Hauth, J. C., Parker, C. R., Jr., MacDonald, P. C., Porter, J. C., and Johnston, J. M.: A role of fetal prolactin in lung maturation. Obstet. Gynecol., 51: 81 (1978).

9. Liggins, G. C.: Premature delivery of feotal lambs infused with glucocorticoids. J. Endocrinol., 45: 515 (1969)

10. Liggins, G. C., and Howie, R. N.: A controlled trial of antepartum glucocorticoid treatment for prevention of the respiratory distress syndrome in premature infants. Pediatrics, 50: 515 (1972)

11. Mescher, E. J., Platzker, A. C., Ballard, P. L., Kitterman, J. A., Clements, J. A., and Tooley, W. H.: Ontogeny of tracheal fluid, pulmonary surfactant and plasma corticoids in the fetal lamb. J. Appl. Physiol., 39: 1017 (1975).

12. Motoyama, F. K., Orzalesi, M. M., Kókkawa, Y., Kaibara, M., Wu, B., Zigas, C. J., and Cook, C. D.: Effect of cortisol on the maturation of fetal rabbit lungs. Pediatrics, 48 : 547 (1971).

13. Murphy, B. E. P.: Does the human fetal adrenal play a role in parturition? Am. J. Obstet. Gynecol., 115: 521 (1973).

14. Murphy, B. E. P., Patrick, J., and Clark, S. J.: Cortisol in the human fetus and amniotic fluid. Presented at the 55th Annual Meeting of the Endocrine Society Chicago, IL, June, 1973.

15. Murphy, B. E. P., Patrick, J., and Denton, R. L. Cortisol in amniotic fluid during human gestation. J. Clin. Endocrinol. Metab., 40: 164 (1975).

16. Oldenborg, V., and van Golde, L. M.: Activity of cholinephosphotransferase, lysolecithin, lysolecithin acyltransferase and lysolecithin acyltransferase in the developing mouse lung. Biochim. Biophys. Acta, 441 : 433 (1976).

17. Platzker, A. G., Kitterman, J. A., Mescher, J., Clements, J. A., Tooley, W. H.: Surfactant in the lung and tracheal fluid of the fetal lamb and acceleration of its appearance by dexamethasone. Pediatrics, 56: 554 (1975).

18. Rooney, S. A., Wai-Lee, T. S., Gobran, L., and Motoyama, E. K... Phospholipid content, composition and biosynthesis during fetal lung development in the rabbit. Biochim. Biophys. Acta, 431: 447 (1976).

19. Schultz, F. M., Jimenez, J. M., MacDonald, P. C., and Johnston, J. M.: Fetal lung maturation. I. Phosphatidic acid phosphohydrolase in rabbit lung. Gynecol. Invest., 5: 222 (1974).

20. Requests for reprints should be addressed to: Dr. Raúl Bustos, Centro Latinoamericano de Perinatologia y Desrraollo Humano, Casilia de Correo 627, Montevideo, Uruguay.

21. Received for publication June $24,1980$.

22. Accepted for publication October 27, 1980. 